\title{
Quality, mainstream services with proactive and targeted outreach: A model of contraceptive service provision for young people
}

\author{
Paula Baraitser, MBBS, MFF, Senior Clinical Medical Officer, Department of Reproductive Health, Community Health South \\ London NHS Trust, St Giles Hospital, London, UK; Rachael Fettiplace, Medical Student, Guys, Kings and St Thomas'Schools \\ of Medicine and Dentistry, London, UK; Frances Dolan, SRN, FP Cert, Sexual Health Outreach Worker, Department of \\ Reproductive Health, Community Health South London NHS Trust, St Giles Hospital, London, UK; Helen Massil, MRCOG, MFFP, \\ Director/Consultant, Department of Reproductive Health, Community Health South London NHS Trust, St Giles Hospital, \\ London, UK; Sarah Cowley, BA, PhD, Professor of Community Practice Development, Florence Nightingale School of Nursing \\ and Midwifery, Kings College London, London, UK
}

Correspondence: Paula Baraitser, SCMO, Department of Reproductive Health, Community Health South London NHS Trust, St Giles Hospital, St Giles Road, Camberwell, London SE5 7RN, UK. E-mail: Paula.Baraitser@chsltr.sthames.nhs.uk

(Accepted $12^{\text {th }}$ February 2002)

The Journal of Family Planning and Reproductive Health Care 2002: 28(2): 90-94

\begin{abstract}
Introduction. High teenage pregnancy rates in the UK reflect low levels of contraceptive use. Young people have a negative perception of contraceptive services and experience significant practical barriers to their use. Dedicated young people's services are considered an effective way to improve access. However it is costly to provide two parallel services (one for older and one for young clients) and competition for resources between two services limits the opening hours of both. In this way access by clients of all ages may be reduced. We have piloted an alternative approach. We provide quality mainstream services (open to clients of all ages) with extended hours and no appointment necessary. This is combined with targeted outreach to facilitate access by the under-25s. The outreach programme includes the development of close links between the clinic and local schools, youth services, social services and voluntary sector organisations. This paper presents one part of the evaluation of this service.

Methods. Patients registering in the 6 months before and 18 months after the development of the new service completed an anonymous questionnaire. This collected demographic details and data on their source of information about the service.

Results. The number of clients of all age groups registering at the new service in the first year doubled. The number of new users aged under 16 years increased by 12-fold in the first 18 months. The number of young people citing a school sex education class as their source of information about the clinic increased by more than five-fold.

Conclusion. This model of contraceptive service provision significantly increases service access by young people. It represents an effective alternative to dedicated services for young people.
\end{abstract}

\section{Key message points}

- Drop-in contraceptive services with extended hours increase access for clients of all age groups.

- Quality mainstream services combined with targeted outreach effectively attract young people to contraceptive clinics.

- Developing links between contraceptive services and local schools increases clinic use by school pupils.

\section{Introduction}

Rates of unintended pregnancy and abortion among young people in the UK are the highest in Western Europe. The rate of teenage births in the UK is twice that in Germany, three times that in France and six times the Dutch rate. ${ }^{1}$ Teenage conception rates in the London Borough of Lewisham are the eighth highest in England and Wales. ${ }^{2}$

The Government has identified the teenage conception rate as a significant health problem and has set a goal of reducing by half the rate of conceptions among under-18s by 2010 . The negative consequences of teenage pregnancy for young women include:

- Health risks: hypertension, anaemia, obstetric complications, poor nutrition, depression and isolation.

- Educational risks: school drop-out and gaps in education.

- Socio-economic risks: reduced employment opportunities and poorer housing. ${ }^{3}$

Use of contraception among young people remains suboptimal with non-use of contraception at first intercourse reported by $18 \%$ of men and $22 \%$ of women aged 13-14 years at occurrence. ${ }^{4}$ One reason for this is the barriers experienced by young people in accessing contraceptive services. These include young people's negative perception of clinical services, for example, as judgmental, unwelcoming or insufficiently confidential, and practical barriers to service access including inappropriate opening hours and a need for appointments. 5

In many settings the response to high teenage pregnancy rates has been the development of dedicated young people's clinics. This approach is advocated by the Teenage Pregnancy Unit of the Department of Health ${ }^{6}$ on the basis of consultation with young people. ${ }^{7,8} \mathrm{We}$ considered this approach to the development of our own service but were concerned that the provision of two parallel services (one for younger people and one for older) could be inefficient and inappropriate for the following reasons:

- Duplication of clinical services results in an inefficient use of resources.

- Limited resources restrict young people's clinics to a small number of sessions per week. These are unlikely to meet the needs of clients who require rapid access to services. 
- It may restrict young people's access to services by implying that they are not welcome to use mainstream services.

- It reinforces the perception that young people should not be open about their sexual activity (an argument given in support of dedicated services is that it guarantees that young people will not meet older friends or relations).

- Young people's services are advertised as being confidential, welcoming, friendly and non-judgmental, yet these should be the advantages of all good-quality contraceptive services.

- Many young people's services focus on teenagers, yet the highest abortion and sexually transmitted infection rates occur in women aged $20-24$ years. ${ }^{3}$

In Lewisham we have piloted an alternative approach to the provision of contraceptive services for young people. This model consists of a 'drop-in' (no appointment) clinical service that is open extended hours including lunchtimes, evenings and after school. This reduces the practical barriers to service use by young people. This is combined with the development of partnerships via outreach work between the clinic service and local organisations (statutory and voluntary) working with young people. This 'repositions' the clinic within the community rather than outside it and supports young people's access to the service.

We anticipated that these changes would result in increased service use by local young people.

\section{Quality mainstream services with proactive and targeted outreach}

We extended the opening hours at our largest centre in North Lewisham from 21 to 39 hours per week. We prioritised opening after school, at lunchtimes and evenings. This was possible with only a $30 \%$ increase in staffing levels by moving three poorly utilised sessions into the larger centre, stretching double-doctor sessions into two single-doctor sessions and introducing nurse-led clinics. In addition, a full-time administrator was employed who took on some duties previously done by clinical staff, for example, ordering. The new service also benefited from economies of scale; for example, the time taken to set up and clear away a clinic is similar whether the clinic has been open for one session or all day.

We aimed to facilitate the use of the new service by young people through a targeted outreach programme. This aimed specifically to link the clinic with local organisations working with young people (including schools). The innovative aspects of the outreach were:

- It linked a specific clinic to a local community. Whereas our past outreach was diffuse this project linked a group of organisations in a specified area to their local clinic.

- It was proactive. Whereas before we waited for requests for outreach, this project generated and maintained upto-date lists of local organisations. These organisations were contacted regularly by the outreach nurse who offered a flexible programme of interventions.?

- The employment of a clinical outreach worker (i.e. a family planning nurse rather than a youth worker). This provided the opportunity to meet a member of clinic staff who had expert sexual health knowledge and an understanding of how local services operate at all outreach sessions

As a result relationships were built with a wide variety of local organisations working with young people. Examples included the school truancy prevention project, the youth offending team, the local adventure playground, and organisations providing work experience for those doing badly at school. An extensive sex and relationship education programme was implemented in local schools including a drop-in advice session at one school. The outreach programme has been extensively evaluated. One part of this evaluation has been published, ${ }^{9}$ the remainder is in preparation.

\section{Evaluating the new service}

Evaluating the complex effects of changes in sexual health service provision presents a number of methodological challenges. These have contributed to the current lack of information on the relative effectiveness of different models of sexual health provision for young people. ${ }^{9-11}$ One of the most significant difficulties is the impossibility of showing a change in teenage pregnancy rates as a result of small projects. In Evelyn ward where the clinic is situated the number of conceptions among girls aged 13-17 years during the three-year period 1995-1997 was 46.2. Because of the small numbers of actual conceptions the $95 \%$ confidence limits for this figure are $33.8-60.4 .^{2}$ This means that even if a $20 \%$ decrease in the rate occurs as a result of the project, the confidence intervals of the new rate (36.76) are likely to overlap with those for the 1995-1997 rate. The change will therefore not be statistically significant.

Our evaluation of this project has been previously discussed in the Journal of Family Planning and Reproductive Health Care. ${ }^{9}$ We have taken a developmental approach that includes the collation of several different types of data. This paper presents the results of part of the evaluation: a questionnaire to all new patients. The aim was to document changes in the number of new clinic users as a result of the project, their age, postcodes and source of information about the new service.

\section{Methods}

All new patients using the service from 6 months before the changes were implemented to 18 months afterwards were given an anonymous, self-completion questionnaire at the time of registration. This asked for demographic details and the source of their information about the clinic. Data on new patient registrations at the individual clinics prior to the project is taken from clinics lists of new patient registrations.

\section{Results}

During the period 1 April 1999 to 31 March 2001 a total of 2978 questionnaires were completed. During this time 3908 new patients registered at the clinic, giving a response rate of $76.2 \%$.

The project had an immediate effect on the number of new clients using the service, with new patient registration at the amalgamated clinic more than double the sum of new patient registration at the four sites prior to amalgamation (Table 1). The data on new patient registration before amalgamation are

Table 1 New patient registrations before (from clinic patient registration data) and after (from questionnaires) the relocation of New Cross, Heathside and Lind clinical sessions into the Waldron Clinic

\begin{tabular}{lcl}
\hline Clinic & $\begin{array}{l}\text { Number of new patients } \\
\text { prior to amalgamation of } \\
\text { clinics (1 April 1998- } \\
\text { 1 April 1999) }\end{array}$ & $\begin{array}{l}\text { Number of new patients } \\
\text { after amalgamation } \\
\text { (1 October 1999- } \\
\text { 1 October 2000) }\end{array}$ \\
\hline New Cross & 85 & N/A \\
Lind & 53 & N/A \\
Heathside & 51 & N/A \\
Waldron & 902 & 2297 \\
Total & 1091 & 2297 \\
\hline
\end{tabular}

N/A, Not available. 
taken from clinic registration statistics and relate to the financial year prior to amalgamation. The data on new patient registration after amalgamation are taken from the questionnaire and relate to the calendar year starting on the day that the new amalgamated service opened. The increase in new patient registration was sustained over time. Table 2 shows the continued, steady increases in new patient registration over the 18 months after the start of the project.

Table 2 Number of new patients registering at the expanded clinic before and after project implementation

\begin{tabular}{ll}
\hline Time scale & New clients registering at clinic (n) \\
\hline Six months before project & 280 \\
First 6 months after project & 708 \\
Second 6 months after project & 872 \\
Third 6 months after project & 959 \\
\hline
\end{tabular}

New patient registration increased among all age groups but the relative proportions of older and younger new users changed. The proportion of new under 16-year-olds registering at the clinic increased. The proportion of new over 30-year-olds registering decreased (Table 3 ).

A comparison of the number of new users in the 6 months before the project started and the third 6-month period after it was implemented shows that:

- New users aged under 16 years increased by 12 -fold.

- New users aged 16-19 years increased by 3-fold.

- New users aged over 30 years increased by 2.5 -fold.

The increase in clinic users that occurred as soon as the new service opened raises questions about how new clients had learnt about the new service.

Our results show that friends are the most significant source of information about clinics for the 16-19-year-old age group, slightly less important for the under-16s and the 20-29-year-old age group and much less important for the over-30s. One-third of under-16s and $15 \%$ of the 16-19-year-old group cited school sex education classes as their source of information about the clinic. One-third of the 20-29-year-old group and almost half of the over30 s cited their general practice as their source of information. This source was very uncommonly cited by the very young and by only $11 \%$ of the $16-19$-year-olds.

The source of information about the clinic also varied with time. The number of young people citing a school sex education class as their source of information about the clinic increased by more than five-fold once the outreach worker started developing existing links with local schools at the start of the project (Table 5), and the percentage of new users citing a friend as their source of information increased steadily over time.

Most new users lived near to the clinic. A total of $68 \%$ had postcodes in areas immediately adjacent to the clinic. A further $19 \%$ of new users came from South East London, with the remaining 13\% from outside South East London.

\section{Discussion}

The combination of extended clinic hours, open access services and proactive, targeted outreach has significantly increased use of community family planning services in North Lewisham. The increases in new patient registration that occurred as soon as the new service opened suggests an unmet need for quality contraceptive services prior to the project. Service use among clients of all age groups increased but was particularly significant among the very young.

An increasing proportion of new young users heard about the new service from sex education classes. The outreach programme linking the clinic with local schools prioritised the knowledge and skills required for clinic access as learning objectives. Some lessons were clinic-based and all provided an opportunity for pupils to meet clinic staff.

Qualitative data from other parts of the evaluation suggest that the changes in opening hours and drop-in system are attractive to all users but particularly to the very young. This is consistent with published data on users' views of an ideal service. ${ }^{7,8}$ Despite the outreach worker's attempts to inform local young people that she was available to fast track them through the service at certain times, they had great difficulty in retaining this information.

Table 3 New clients in each age group as a percentage of the total number of new clients ${ }^{a}$

\begin{tabular}{|c|c|c|c|c|}
\hline Age (years) & $\begin{array}{l}\text { Percentage before } \\
\text { project }(\mathrm{n})\end{array}$ & $\begin{array}{l}\text { Percentage in first } \\
6 \text { months (n) }\end{array}$ & $\begin{array}{l}\text { Percentage in second } \\
6 \text { months (n) }\end{array}$ & $\begin{array}{l}\text { Percentage in third } \\
6 \text { months (n) }\end{array}$ \\
\hline$<16$ & $2.1(6)$ & $10.0(71)$ & $7.9(69)$ & 7.7 (74) \\
\hline $16-19$ & $22.5(63)$ & $20.9(148)$ & $22.0(191)$ & $24.3(233)$ \\
\hline $20-29$ & $40.3(113)$ & $44.5(315)$ & $45.2(395)$ & $42.0(401)$ \\
\hline $30+$ & $33.0(92)$ & $23.2(164)$ & $24.1(210)$ & $24.1(231)$ \\
\hline Total & $97.9(274)$ & $98.6(698)$ & $99.2(865)$ & $98.1(939)$ \\
\hline
\end{tabular}

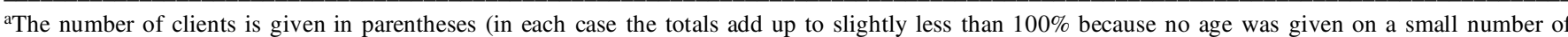
questionnaires).

Table 4 Source of information about the clinic among new users aged $<16$ years ${ }^{a}$

\begin{tabular}{|c|c|c|c|c|}
\hline $\begin{array}{l}\text { Source of information about } \\
\text { the clinic }\end{array}$ & $\begin{array}{l}\text { Percentage of under } \\
16 \text {-year-olds citing } \\
\text { this source }(n)\end{array}$ & $\begin{array}{l}\text { Percentage of } 16-19- \\
\text { year-olds citing this } \\
\text { source }(n)\end{array}$ & $\begin{array}{l}\text { Percentage of } 20-29- \\
\text { year-olds citing this } \\
\text { source }(n)\end{array}$ & $\begin{array}{l}\text { Percentage of respondents } \\
\text { aged } 30+\text { years citing this } \\
\text { source }(n)\end{array}$ \\
\hline Friend & $42 \quad(136)$ & $(459)$ & $41 \quad(526)$ & $26(187)$ \\
\hline School sex education class & $29.7(96)$ & $15 \quad(87)$ & $0.7(9)$ & $0.8(6)$ \\
\hline General practice & $3.7(12)$ & $11.0(65)$ & $31.8(404)$ & 45.7 (333) \\
\hline School nurse & 5.9 (19) & $2.5(15)$ & $0.4(5)$ & $0 \quad(0)$ \\
\hline Service leaflet & $8.7(28)$ & $7.2(42)$ & $6.4(81)$ & $8.5(62)$ \\
\hline Relative & $6.2(20)$ & $8.3(48)$ & $4.0(51)$ & $4.5(33)$ \\
\hline Sign in the health centre & 3.7 (12) & $4.4(26)$ & $4.6(59)$ & $5.7(42)$ \\
\hline NHS Direct & $1.2(4)$ & $1.2(7)$ & $1.7(22)$ & $4.1(11)$ \\
\hline Yellow pages & $2.2(7)$ & $4.7(27)$ & $6.7(85)$ & $4.9(36)$ \\
\hline
\end{tabular}

aThe percentage values do not add up to $100 \%$ because many respondents cited more than one source of information. 
Table 5 Percentage of the total number of users citing friends and schools as source of information in 6-month periods

\begin{tabular}{|c|c|c|c|c|}
\hline $\begin{array}{l}\text { Source of information about } \\
\text { the clinic }\end{array}$ & $\begin{array}{l}\text { Percentage } 6 \text { months } \\
\text { before project }(n)\end{array}$ & $\begin{array}{l}\text { Percentage in first } \\
6 \text { months after the } \\
\text { project }(n)\end{array}$ & $\begin{array}{l}\text { Percentage in second } \\
6 \text { months after the } \\
\text { project }(n)\end{array}$ & $\begin{array}{l}\text { Percentage in third } \\
6 \text { months after the } \\
\text { project (n) }\end{array}$ \\
\hline $\begin{array}{l}\text { Friend } \\
\text { School sex education class }\end{array}$ & $\begin{array}{l}39.6(111) \\
3.6(10)\end{array}$ & $\begin{array}{l}40.8(289) \\
7.8(55)\end{array}$ & $\begin{array}{l}46.7(408) \\
7.0(61)\end{array}$ & $\begin{array}{l}48.1(461) \\
7.0(68)\end{array}$ \\
\hline
\end{tabular}

\section{Mainstream services with proactive and targeted outreach: a model of contraceptive service provision for young people}

The success of this pilot study calls for the debate on the relative merits of centralised versus local and targeted versus mainstream services to be revisited.

Centralised services are open for long hours but may require clients to travel an unacceptable distance to access them. Local services are situated close to users' homes but provide relatively few sessions per week. Our service represents a compromise providing a semi-centralised, extended-hours service serving a limited area approximately $50 \%$ of that covered by a Primary Care Trust (PCT).

Targeted services aim to meet the needs of specific client groups. Mainstream services aim to meet the needs of a range of users. Ideally this is achieved by providing a flexible service responsive to individual client needs.

The argument for targeted services for young people is the opportunity to prioritise those aspects of service provision, which are especially important to young clients such as confidentiality or non-judgmental attitudes from clinic staff. However these are the basic elements of all quality contraceptive services. Clinics where regular breaches of confidentiality occur or where staff comment on the sexual lifestyles of their patients are offering care of an unacceptably low standard.

The idea of prioritising the specific needs of the group 'young people' assumes a homogeneity of need which may not exist beyond the basic attributes of a high-quality service as in the example above. It is more likely that multiple subgroups of this population have needs which differ, for example, according to their age, sex, ethnicity or previous sexual experience. The challenge for targeted services to meet these multiple different needs then becomes similar to that faced by mainstream service providers.

There are also practical problems that restrict the provision of targeted services. These relate primarily to the cost of running two parallel services (one for younger and one for older users) which are open for sufficient time to ensure adequate access.

The results presented here suggest that mainstream contraceptive services are attractive to young people if they are of sufficient quality and if initial access is facilitated by targeted outreach. They suggest a possible direction for service development suitable particularly for contraceptive services in urban areas where access by young people is suboptimal.

\footnotetext{
Statements on funding and competing interests

Funding. None declared.

Competing interests. Paula Baraitser was involved in developing the model described here. Frances Dolan is the sexual health outreach nurse for the project.

References

Social exclusion unit report on teenage pregnancy. London: Her Majesty's Stationery Office

LSLHA Sexual Health Bulletin 3. Small area analyses and maps - STI and conception data.

Lambeth, Southwark and Lewisham Health Authority, May 2000. Teenage Pregnancy Unit. $R$.

Wellings K, Nanchahai K, Macdowall W, et al. Sexual behaviour in Britain: early heterosexual experience. Lancet 2001; 358: 1843-1850.

experience. Lancet $2001 ; 358: 1843-1850$.
Aggleton P, Oliver C, Rivers K. Reducing the rate of teenage conceptions: the implications of research into young people, sex, sexuality and relationships. London: Health Education Authority, 1998

Teenage Pregnancy Unit. Best Practice Advice on the Provision of Effective Contraception and Advice Services for Young People. http://www.tap.ccta.gov.uk/doh/info.nsf.fdb.

Egg Research and Consultancy. 'Someone with a smile would be your best bet'; what young people want from sex advice services. London: Brook Advisory Centres, 1998.

Smith A. Young people's contraception and sexual health: report of a local needs assessment in Staveley, North Derbyshire. J Fam Plann Reprod Health Care 2001; 27: 29-33.

Baraitser P, Dolan F, Feldman R, et al. Sexual health in a playground: lessons learnt from the evaluation of a small-scale sexual health project. J Fam Plann Reprod Health Care 2002; 28: $18-22$.

10 Peckham S. Preventing unintended teenage pregnancies. Public Health 1993; 107: 125-133.

1 NHS Centre for Reviews and Dissemination. Preventing and reducing the adverse effects of unintended teenage pregnancies. 1997; 3: 1 .
} 